\title{
Raised temperature reduces the incidence of diabetes in the NOD mouse
}

\author{
A.J.K. Williams ${ }^{1}$, J. Krug ${ }^{1,2}$, E. F. Lampeter ${ }^{1,2}$, K. Mansfield ${ }^{3}$, P.E. Beales ${ }^{1}$, \\ A. Signore ${ }^{4}$,E. A. M. Gale ${ }^{1}$ and P. Pozzilli ${ }^{1,4}$ \\ ${ }^{1}$ Department of Diabetes and Immunogenetics and ${ }^{3}$ Animal Services Unit, St. Bartholomew's Hospital, London, UK, and \\ ${ }^{2}$ City Hospital, Leipzig, FRG and ${ }^{4}$ Cattedra Endocrinologia, II Clinica Medica University of Rome, "La Sapienza", Rome, Italy
}

Summary. An association between the incidence of childhood Type 1 (insulin-dependent) diabetes mellitus and the average yearly temperature in different countries has been reported, the incidence being higher in countries with a lower mean temperature. We have studied the effect of environmental temperature on the incidence of diabetes in an animal model of Type 1 diabetes, the non-obese diabetic (NOD) mouse. Female NOD mice were divided at weaning, with one group placed at a higher temperature (mean $23.7 \pm 1.7^{\circ} \mathrm{C}$ ) and the other at a lower temperature $\left(21.0 \pm 1.8^{\circ} \mathrm{C}\right)$. At 20 weeks of age 6 of 16 mice at lower temperature and 1 of 17 mice at higher temperature had developed diabetes $(p<0.02)$; at 30 weeks 10 of 16 and 5 of 17 mice had developed diabetes $(p<0.05)$. Non-diabetic animals in the low temperature group had a higher food intake than those in the high temperature group between 13-15 weeks of age $(28.0 \pm 1.2 \mathrm{~g} /$ week vs $24.8 \pm 0.7 \mathrm{~g} /$ week, $p<0.05)$. In a parallel experiment, histological examination showed that there were similar degrees of insulitis in the high and low temperature groups at seven weeks of age. We conclude that environmental temperature can affect the incidence of diabetes in the NOD mouse and that this may be related to alterations in food intake.

Key words: Type 1 (insulin-dependent) diabetes mellitus, environmental temperature, non-obese diabetic (NOD) mouse.
Type 1 (insulin-dependent) diabetes mellitus develops from an interaction of genetic, immunological and environmental factors [1]. Epidemiological studies can suggest possible causes but analysis is complicated by marked genetic variations both within and between populations. Animal models provide a useful tool with which to investigate the influence of environmental factors against a homogeneous genetic background. Diet and stress are among the factors that have been shown to influence the course of this disease in animal models $[2,3]$.

The stimulus for this study was provided by the report of the Diabetes Epidemiology Research International Group (DERI) which provided the first set of standardized incidence estimates of Type 1 diabetes among divergent areas and ethnic groups [4]. They showed associations with latitude and average yearly temperature, such that the incidence of childhood Type 1 diabetes was higher in countries with a lower average yearly temperature. The aim of our study was therefore to investigate whether environmental temperature affects the incidence of diabetes in the non-obese diabetic (NOD) mouse, an animal model which shares several genetic, immunologi- cal and clinical characteristics with human Type 1 diabetes.

\section{Materials and methods}

Our NOD mouse colony was established in 1987 and derived originally from the colony of Dr. E. Leiter (Jackson Laboratory, Bar Harbor, Me, USA). The colony, which has been maintained by parallel line in-breeding, is characterised by the onset of insulitis at $3-5$ weeks of age and the onset of clinical diabetes from approximately 10 weeks of age. There is a stable cumulative incidence of diabetes in females which approaches $50 \%$ at 30 weeks of age $(47.4 \pm 3.6 \%)$, with a peak of incidence at 22 weeks.

Forty female NOD mice were split into two litter matched groups at weaning, with four animals per cage. One group of animals, designated the high temperature group was placed near a radiator with extra bedding. The other, low temperature group was placed away from the radiator, near the door. Room temperature was recorded daily using maximum/minimum thermometers placed with each group. The animals were fed laboratory chow ad libitum, with a protein content of $19 \%$ and a mean energy content of approximately $3000 \mathrm{KCal} / \mathrm{Kg}$ (Grain Harvesters Ltd, Wingham, UK); food intake was measured from the thirteenth week of age. Urinary glucose measurements were made weekly from the eleventh week of age and diabetes diagnosed on finding levels of glucosuria greater than 


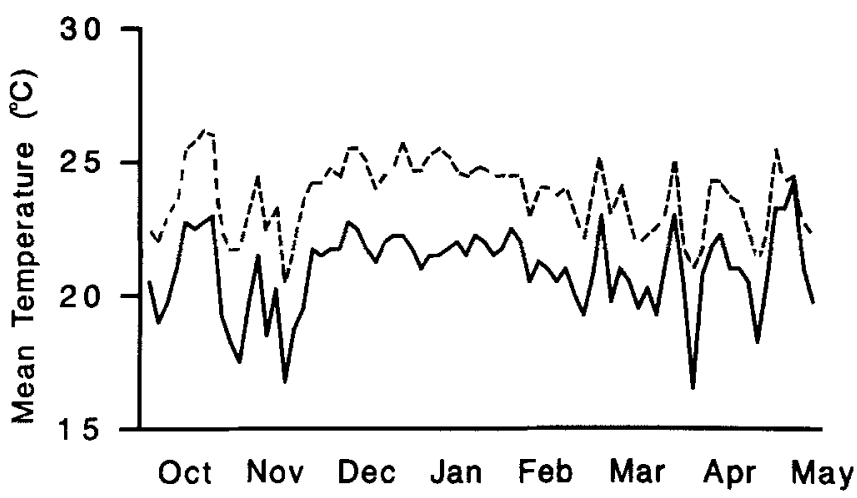

Fig. 1. The mean ambient temperature of the high (broken line) and low (solid line) temperature groups throughout the period of the study. The average mean temperature difference was $2.8^{\circ} \mathrm{C}$ $(p<0.0001)$

$1 \mathrm{~g} / 100 \mathrm{ml}$ on more than one occasion. (Diaburstix, BoehringerMannheim, FRG).

Fourteen litter matched female mice were set up according to the same protocol but killed at seven weeks of age. Pancreata were removed, frozen in liquid nitrogen and stored at $-70^{\circ} \mathrm{C}$ for histological investigation. Ten $6 \mu \mathrm{m}$ cryocut sections from different areas of each pancreas were prepared and stained with haematoxylin/eosin. The islets in each section were screened "blind" for lymphocytic infiltration and classified according to the severity of insulitis. The percentage of islets in relation to the degree of lymphocytic infiltration (absent, mild or severe) was measured for each mouse and the average for each group was calculated as described elsewhere [5].

\section{Statistical analysis}

For statistics paired $t$-test and comparison of proportion were used as appropriate. The incidence of diabetes in the colony was calculated using life-table analysis.

\section{Results}

The mean high temperature was $23.7 \pm 1.7^{\circ} \mathrm{C}$ and the mean low temperature $21.0 \pm 1.8^{\circ} \mathrm{C}(p<0.0001)$ (Fig.1). The average mean temperature difference achieved throughout the period of the study was $2.8^{\circ} \mathrm{C}$ (although the effective temperature difference would be greater due to the extra bedding given to the animals in the high temperature group). Figure 2 shows the cumulative incidence of diabetes in the mice kept at different temperatures. Deaths, unrelated to diabetes, reduced the number of animals in each group to 17 matched pairs, before 11 weeks of age. One non-diabetic mouse in the low temperature group died at 17 weeks of age and has been excluded from calculations of diabetes incidence. At 20 weeks of age 6 of 16 mice in the low temperature group had developed diabetes as compared to 1 of 17 mice in the high temperature group $(p<0.02)$. At 30 weeks of age 10 of 16 mice in the low temperature group and 5 of 17 mice in the high temperature group had developed diabetes; this difference was still significant $(p<0.05)$. Non-diabetic animals in the low temperature group ate an average of $3.2 \mathrm{~g} /$ week more than those in the high temperature group
A.J.K. Williams et al.: Temperature affects diabetes in NOD mice

$(28.0 \pm 1.2 \mathrm{~g} /$ week vs $24.8 \pm 0.7 \mathrm{~g} /$ week, $p<0.05)$. Neither the percentage of infiltrated islets $(53.4 \pm 7.4 \%$ vs $51.8 \pm 8.2 \%$ ) nor the severity of insulitis differed between the two groups at seven weeks of age (mild $25.4 \pm 3.9 \%$ vs $23.6 \pm 0.6 \%$, moderate $17.5 \pm 4.6 \%$ vs $17.6 \pm 4.3 \%$, severe $10.7 \pm 5.3 \%$ vs $10.6 \pm 4.3 \%)$.

\section{Discussion}

Changes in environmental temperature within the physiological range may be responsible for a significant difference in diabetes incidence in the NOD mouse. Animals kept at a higher temperature have a lower incidence of diabetes than those kept at a lower temperature. This difference could be due to metabolic or immunological mechanisms, although there is now some evidence to suggest that these may be interlinked.

Mice provided with food ad libitum eat less when kept at higher temperature, since they require less energy to maintain their body temperature. This, together with a reduction in counterregulatory hormones, may alleviate stress on the compromised Beta cells and delay the onset of diabetes. A similar mechanism has been proposed to explain both seasonal variations in incidence [6] and the pubertal peak in incidence in man [7].

Alternatively, reduced food intake may have a direct effect upon the autoimmune process. Some constituents of chow diet have been shown to be diabetogenic in the NOD mouse. Indeed, purified or semi-purified diets can reduce the incidence of diabetes and the degree of insulitis in this animal model [2].

Lower food intake may cause a decrease in Beta-cell function, leading to decreased target Beta-cell autoantigen expression, thereby reducing the autoimmune response towards Beta cells [8]. However, the histological findings indicate that the severity of insulitis is not affected by this difference in temperature at 7 weeks of age. Although the number of animals investigated was small,

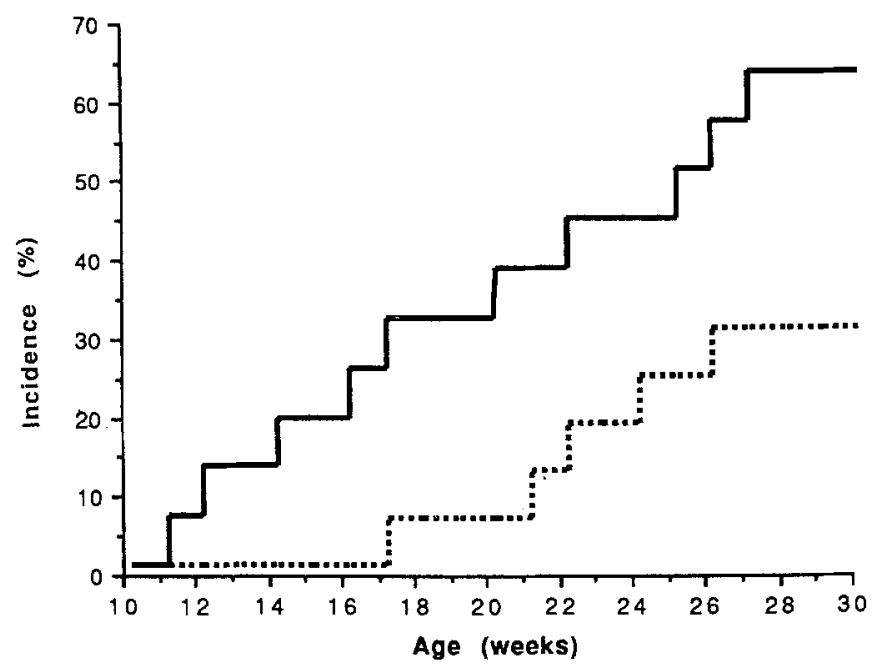

Fig. 2. The cumulative incidence of diabetes in 17 female mice kept at high (broken line) and 16 female mice at low (solid line) temperature from 10 to 30 weeks of age. The difference in incidence was significant at $20(p<0.02)$ and at 30 weeks $(p<0.05)$ 
this observation suggests that the temperature difference does not modify the natural history of insulitis and probably does not influence early pathogenic events. However, this does not exclude the possibility that the resistance of Beta cells to immunological attack and/or their capacity to regenerate may be altered [9].

Viral infection is known to affect the incidence of diabetes in the NOD mouse [10] and since our colony is not kept in pathogen free conditions, infection remains a possible explanation for the difference in incidence. It is also possible that other less obvious environmental factors may have influenced the outcome of this experiment. For example, the proximity of the low temperature group to the door, possibly associated with an increase in stress, could have promoted the incidence of diabetes in this group.

In conclusion, this study indicates that differences in temperature, affect the incidence of diabetes in an animal model of Type 1 diabetes, the NOD mouse. The lower incidence at higher temperature may be due to reduced food intake before the onset of diabetes. The mechanisms underlying this effect require investigation since they may help to explain geographical variation in childhood Type 1 diabetes in man.

Acknowledgements. We would like to thank Mr. T. Ward, Dr. P.Bingley and Mrs. P. Patel for their help and advice. This work was supported by grants from the Joint Research Board, St. Bartholomew's Hospital and the C. N. R. of Italy, Progetto Bilaterale n. 88.00617.04.

\section{References}

1. Maclaren N, Schatz D, Drash A, Grave G (1989) Initial pathogenic events in IDDM. Diabetes 38: 534-538
2. Coleman DL, Kuzava JE, Leiter EH (1990) Effect of diet on incidence of diabetes in nonobese diabetic mice. Diabetes 39 : 432-436

3. Carter WR, Herrman J, Stokes K, Cox DJ (1987) Promotion of diabetes onset by stress in the BB rat. Diabetologia 30: 674-675

4. Diabetes epidemiology research international group (1988) Geographic patterns of childhood insulin-dependent diabetes mellitus. Diabetes 37: 1113-1119

5. Signore A, Pozzilli P, Gale EAM, Andreani D, Beverley PCL (1989) The natural history of lymphocyte subsets infiltrating the pancreas of NOD mice. Diabetologia 32: 282-289

6. MacDonald MJ, Liston L, Carlson I (1987) Seasonality in glycosylated haemoglobin in normal subjects. Does seasonal incidence in insulin-dependent diabetes suggest specific etiology? Diabetes 36: 265-268

7. Smith CP, Archibald HR, Thomas JM, Tarn AC, Williams AJK, Gale EAM, Savage MO (1988) Basal and stimulated insulin levels rise with advancing puberty. Clin Endocrinol 28:7-14

8. Buschard K, Brogren C-H, Ropke C, Rygaard J (1988) Antigen expression of the pancreatic beta cells is dependent on their functional state, as shown by a specific, BB rat monoclonal autoantibody IC2. Acta Pathol Microbiol Immunol Scand 96: 342-346

9. Gorray KC, Maimon J, Schneider BS (1989) Does guinea pig (GP) islet B-cell regeneration following Alloxan ( $\mathrm{AX}$ ) treatment depend upon the fasting-refeeding (FR) paradigm? Diabetes 38 [Suppl2], 162 A (Abstract)

10. Oldstone MBA (1988) Prevention of Type 1 diabetes in non obese diabetic mice by virus infection. Science 239: 500-502

Received: 18 April 1990

and in revised form: 15 June 1990

Dr. P.Pozzilli

P.O. Box 680

I-00187 Rome

Italy

\section{Errata}

\section{Diabetologia, Volume 33, Number 3, March 1990, pp. 148-151}

G. Sundkvist et al.: "The activity of the renin-angiotensin-aldosterone system before and during submaximal bicycle exercise in relation to circulatory catecholamines in patients with Type 1 (insulindependent) diabetes mellitus

Please note that the Angiotensin II concentration in the paper above has been given as $\mathrm{nmol} / \mathrm{h}$ and not as $\mathrm{pmol} / \mathrm{l}$; $\mathrm{pmol} / \mathrm{l}$ is correct and not nmol/l.
Diabetologia, Volume 33, Supplement, August 1990

Abstracts of the 26th Annual Meeting of the European Association for the Study of Diabetes, Copenhagen, Denmark, 10-14 September 1990

During production of the Supplement the page showing abstracts P811-P814 was unfortunately printed after abstract P794. 